\title{
Physical activity energy expenditure has not declined since the 1980s and matches energy expenditures of wild mammals.
}

Citation for published version (APA):

Westerterp, K. R., \& Speakman, J. R. (2008). Physical activity energy expenditure has not declined since the 1980s and matches energy expenditures of wild mammals. International Journal of Obesity, 32(8), 1256-1263. https://doi.org/10.1038/ijo.2008.74

Document status and date:

Published: 01/01/2008

DOI:

10.1038/ijo.2008.74

Document Version:

Publisher's PDF, also known as Version of record

\section{Document license:}

Taverne

Please check the document version of this publication:

- A submitted manuscript is the version of the article upon submission and before peer-review. There can be important differences between the submitted version and the official published version of record.

People interested in the research are advised to contact the author for the final version of the publication, or visit the DOI to the publisher's website.

- The final author version and the galley proof are versions of the publication after peer review.

- The final published version features the final layout of the paper including the volume, issue and page numbers.

Link to publication

\footnotetext{
General rights rights.

- You may freely distribute the URL identifying the publication in the public portal. please follow below link for the End User Agreement:

www.umlib.nl/taverne-license

Take down policy

If you believe that this document breaches copyright please contact us at:

repository@maastrichtuniversity.nl

providing details and we will investigate your claim.
}

Copyright and moral rights for the publications made accessible in the public portal are retained by the authors and/or other copyright owners and it is a condition of accessing publications that users recognise and abide by the legal requirements associated with these

- Users may download and print one copy of any publication from the public portal for the purpose of private study or research.

- You may not further distribute the material or use it for any profit-making activity or commercial gain

If the publication is distributed under the terms of Article $25 \mathrm{fa}$ of the Dutch Copyright Act, indicated by the "Taverne" license above, 


\title{
ORIGINAL ARTICLE
}

\section{Physical activity energy expenditure has not declined since the $1980 \mathrm{~s}$ and matches energy expenditures of wild mammals}

\author{
KR Westerterp ${ }^{1}$ and JR Speakman ${ }^{2}$ \\ ${ }^{1}$ Department of Human Biology, Maastricht University, Maastricht, The Netherlands and ${ }^{2}$ School of Biological Sciences, \\ Aberdeen Centre for Energy Regulation and Obesity, University of Aberdeen, Aberdeen, Scotland
}

Objective: Obesity results from protracted energy imbalance. Whether this comprises excessive energy intake, lowered physical activity or both, remains disputed.

Design: Physical activity energy expenditure, evaluated in three different ways from daily energy expenditure (DEE) measured using doubly labelled water, was examined for trends over time. Data included subjects in Europe (Maastricht, the Netherlands) and North America extending back to the 1980s. These data were compared with measures from the third world, and measures made on wild terrestrial mammals.

Results: Physical activity expenditure in Europe (residual of the regression of DEE on basal energy expenditure (BEE)) has slightly but significantly increased since the 1980s. There was no trend over time in physical activity level (PAL $=D E E / B E E)$, or in the residual variance in DEE once mass, sex and age were accounted for. This latter index of physical activity expenditure also significantly increased over time in North America. DEE of individuals in Europe and North America was not significantly different from individuals measured in the third world. In wild terrestrial mammals, DEE mostly depended on body mass and ambient temperature. Predicted DEE for a $78 \mathrm{~kg}$ mammal living at $20^{\circ} \mathrm{C}$ was $9.2 \mathrm{MJ}$ per day $(95 \% \mathrm{Cl}: 7.9-12.9 \mathrm{MJ}$ per day), not significantly different from the measured DEE of modern humans (around 10.2-12.6 MJ per day).

Conclusion: As physical activity expenditure has not declined over the same period that obesity rates have increased dramatically, and daily energy expenditure of modern man is in line with energy expenditure in wild mammals, it is unlikely that decreased expenditure has fuelled the obesity epidemic.

International Journal of Obesity (2008) 32, 1256-1263; doi:10.1038/ijo.2008.74; published online 27 May 2008

Keywords: doubly labelled water method; healthy adults; body size; time trend; wild mammals; physical activity level

\section{Introduction}

In the early 1980 s $8 \%$ of adults in the United States were obese (body mass index $(\mathrm{BMI})>30$ ). By 2005 this prevalence had increased to $22 \% .{ }^{1}$ Similar increases were evident throughout the Western world, ${ }^{2,3}$ and more recent data indicate that the epidemic has spread globally. ${ }^{4}$ Because obesity increases the risk of developing diabetes, ${ }^{5}$ cardiovascular disease ${ }^{6}$ and cancer, ${ }^{7}$ the implications of increases in obesity prevalence are enormous. Estimates of economic costs amount to $5 \%$ of all healthcare spending in most Western societies. ${ }^{8}$ Costs to

Correspondence: Professor KR Westerterp, Department of Human Biology, Maastricht University, PO Box 616, Maastricht 6200 MD, The Netherlands. E-mail: K.Westerterp@HB.Unimaas.NL

Received 18 February 2008; revised 16 April 2008; accepted 20 April 2008; published online 27 May 2008 the wider economy indicate a problem that exceeds tens of billions of dollars in its global impact. ${ }^{9}$ Most researchers agree that obesity is caused by protracted energy imbalance where intake exceeds expenditure. ${ }^{10,11}$ Whether this imbalance is caused by excessive energy consumption, perhaps related to passive over-consumption of foods high in fat that have high energy density and may be less satiating, ${ }^{12,13}$ or due to reduced energy expenditure correlated with our increasingly sedentary lifestyle ${ }^{14,15}$ is unclear. In the past few years, evidence has suggested that the primary problem lies not with increased energy intake ${ }^{15-18}$ but with reduced expenditure, that is reduced physical activity. ${ }^{15,19-21}$

With respect to dietary intake, surveys between the 1970s and 2000s do not indicate that total energy consumption has increased. ${ }^{15,16}$ Moreover, fat consumption seems to have decreased. ${ }^{17,18}$ Unfortunately, most of this evidence is based on self-reported food intakes. Food intake data derived from 
food balance sheets, as used as an indication of national food consumption trends, showed a considerable increase in total energy availability and energy from lipids over the past 40 years. ${ }^{22}$ Differences in trends of total energy supply per capita between countries explained $41 \%$ of the variation of trends in mean BMI. ${ }^{23}$ However, daily energy demands can be measured directly using a method called the doubly labelled water (DLW) technique. ${ }^{24,25}$ When this method was used to compare self-reported energy intakes with energy expenditure, it became clear that energy intake was often considerably underestimated, due to a combination of underrecording and temporary undereating. ${ }^{26,27}$ Importantly, the degree of underestimation of intake was positively related to the BMI of the subjects. Consequently, dietary surveys cannot be used for drawing conclusions on dietary intake over time, or for comparing lean to obese subjects. With respect to physical activity, it became evident that the energy expended on physical activity level (PAL) had also generally been underestimated. Direct observations of the obese suggest they move less than non-obese individuals, however, DLW measurements show that this does not necessarily mean that they spend less energy on physical activity than lean people do, ${ }^{20,21,28}$ because the costs of moving around in the obese are greater, in part because they also have greater lean body mass in addition to greater fat mass.

By measuring daily energy expenditure (DEE) with DLW in combination with basal energy expenditure (BEE) using indirect calorimetry, it is possible to obtain estimates of physical activity energy expenditure in several different ways. One popular index of physical activity is $\mathrm{PAL}=\mathrm{DEE} / \mathrm{BEE}^{29}{ }^{29}$ The PAL normally varies between 1.5 and 2.0. ${ }^{30,31}$ The PAL of modern humans has been previously compared with that of wild mammals, ${ }^{32}$ and on that basis it was suggested that modern humans have lower than expected energy expenditure on activity and hence that lowactivity energy expenditure has fuelled the obesity epidemic. However, this latter study failed to adequately account for body size effects and the effects of ambient temperature on energy demands, a point we shall address in the current paper.

Here we test the hypothesis that reduced levels of physical activity energy expenditure have driven the obesity epidemic. Three separate tests were executed. We compiled data on levels of DEE measured by the DLW method and BEE by respirometry over time in contemporary Western society (Europe and North America) and searched for an effect of year of measurement on indices of activity energy expenditure. Then, we compared the levels of expenditure in modern Western societies with those from the third world countries generally mirroring the physical activity in Western societies in the past. Finally, we compared the levels of expenditure and PAL of modern humans with those of wild terrestrial mammals taking into account both body size and temperature effects.

\section{Methods}

We collected data from four sources for this study. Although the DLW method was first invented in the 1950s, it was not applied to humans until $1982,{ }^{24}$ because the precision and accuracy of mass spectrometry devices prior to that time made the technique too expensive to apply to anything but small animals. We therefore have no direct measures of human energy demands that predate the 1980s. Relatively few sites have continuously studied free-living individuals between the 1980s and the present day, to permit an evaluation of how levels of energy expenditure have changed over the same period that rates of obesity have increased. One such site is the town of Maastricht and surroundings in the Netherlands. The Maastricht protocol for the measurement of DEE in adult subjects with DLW ${ }^{33,34}$ usually covers an interval of 2 weeks. The isotopes are administered as a mixture of ${ }^{2} \mathrm{H}_{2} \mathrm{O}$ (99.9 at\%) and $\mathrm{H}_{2}^{18} \mathrm{O}$ (10 at\%) resulting in an initial excess body water enrichment of 150 p.p.m. for deuterium and 300 p.p.m. for oxygen-18, leaving a sufficient excess enrichment at the end of the observation period. The dose volume is typically $80-160 \mathrm{ml}$ for adults. The isotopes are administered as a last consumption before the night. Subjects provide a background body water sample (blood or urine) immediately before isotope consumption. Then, equilibration takes place overnight and the first post-dosing sample is collected in the early morning, in case of urine from the second voiding. For an observation period of 2 weeks, samples from the second and another voiding on the first, mid and last day of the observation period are sufficient. There are three criteria to judge the validity of the results of isotope analyses for energy expenditure measurements. First, duplicate analyses should not differ more than 1 p.p.m. Typically, the s.d. for replicate samples averages 0.2 and 0.3 p.p.m. for deuterium and oxygen-18, respectively. Secondly, the ratio between the deuterium dilution space and oxygen-18 dilution space is expected to be close to 1.03. As a third criterion, the fit of the isotope elimination curves should be high, or results based on morning and evening samples over corresponding intervals should be close. Carbon dioxide production, as calculated from the isotope elimination rates, is converted to energy expenditure using an energy equivalent based on the substrate mixture oxidized. The protocol allows comparisons of calculated energy expenditure within the first and second week of a 14-day observation period to check for sampling errors. Typically, the difference is smaller than $10 \%$ and samples are re-analyzed when the difference is larger. Validation studies in human subjects reviewed in $^{25}$ reveal the average discrepancy of DLW estimates to simultaneous indirect calorimetry estimates is less than 3\%. Between 1983 and 2005, 366 subjects were measured in Maastricht (first publication 1988) using both the DLW method and direct estimates of their BEE. This sample excludes individuals aged under 18 years, or those involved in interventions in energy intake, physical activity including athletic performance, or 
those that were pregnant, lactating or diseased (Table 1). For studies involving dietary or exercise interventions, only the pre-intervention data or that for control groups was used.

There are three different ways of assessing the physical activity energy expenditure using data on DEE and BEE. The first method is to regress DEE on BEE. The residual variation to the fitted regression directly reflects individual variability in activity energy expenditure. A second popular approach is to calculate the ratio of DEE to BEE called the PAL. Finally, if data on BEE was not available one might make the assumption that most of the variation in DEE once the effects of body mass and sex had been accounted for would be due to differences in physical activity. This is not strictly correct because some of this variation would also reflect differences in BEE that had not been accounted for by body mass or sex. Nevertheless, this provides a third approach for measuring levels of activity energy demands.

Because the Maastricht data were collected from a single site these data are well controlled, but the extent of increase in obesity in the Netherlands over the period that the measurements were made is relatively modest compared to the expansion of obesity elsewhere - such as in the United States. The absence of any trends in DEE in the Maastricht data might therefore be attributed to the measurements being made only in the early phase of an obesity epidemic at this site. As a second source of information therefore we systematically reviewed the literature for data on energy demands in North America. We surveyed all published applications of the method between 1982 and 2005 using databases that include peer-reviewed publications (Medline, PubMed and ISI Web of Science). We searched for papers in these databases using the search terms: doubly labelled water, doubly labeled water, double labelled water and double labeled water to cover both English and American spellings of the term labelled and labeled, respectively. We only searched for articles written in English. We collated copies of the original papers to extract the relevant data for analysis. We excluded any measurements that concerned subjects that were not healthy, and studies where subjects were part of a dietary or physical activity intervention. We also restricted the data to subjects aged between 18 and 50 years. In total we obtained estimates of DEE for 393 subjects across 13 studies, although in many studies the individual data were unavailable and we had access only to means and sample sizes for sub-populations (Table 2). Moreover, a second problem with these data was that BEE data were available for only a small subset of the total sample. Accordingly, we analysed these data using only the third method described above (residual analysis of DEE over time with the effects of body mass, sex and age removed).

Although the data we have analysed for human energy demands stretch back over 20 years and include two sites, one at an early, and the other at an advanced, stage of the obesity epidemic, it might be argued that none of these direct measures of energy expenditure have been made early enough, and that the predisposing change in energy
Table 1 Subject characteristics of Maastricht

\begin{tabular}{lccc}
\hline & Mean & s.d. & Range \\
\hline Women $(n=167)$ & & & \\
Age (years) & 30 & 9 & $18-50$ \\
Height (m) & 1.68 & 0.06 & $1.52-1.86$ \\
Body mass (kg) & 73 & 18 & $47-164$ \\
BMl (kg/m ${ }^{2}$ ) & 26.3 & 6.5 & $16.6-55.3$ \\
DEE (MJ per day) & 10.9 & 1.8 & $7.0-18.4$ \\
& & & \\
Men ( $n=199)$ & & & $18-50$ \\
Age (years) & 33 & 9 & $1.64-1.97$ \\
Height (m) & 1.80 & 0.07 & $50-216$ \\
Body mass (kg) & 83 & 21 & $15.6-61.7$ \\
BMl (kg/m ${ }^{2}$ ) & 25.7 & 6.0 & $9.5-22.6$ \\
DEE (MJ per day) & 14.0 & 2.6 & \\
\hline
\end{tabular}

Abbreviations: BMI, body mass index; DEE, daily energy expenditure.

Table 2 Subject characteristics of studies in North America and the third world

\begin{tabular}{|c|c|c|c|c|}
\hline Reference & $\begin{array}{c}\text { Subjects } \\
\text { (women/men) }\end{array}$ & $\begin{array}{c}\text { Age } \\
\text { (years) }\end{array}$ & $\begin{array}{c}\text { Body } \\
\text { mass }(k g)\end{array}$ & $\begin{array}{c}D E E \\
\text { (MJ per day) }\end{array}$ \\
\hline \multicolumn{5}{|c|}{ North America } \\
\hline \multirow[t]{3}{*}{35} & $13 / 0$ & 31 & 49 & 8.9 \\
\hline & $70 / 0$ & 31 & 58 & 10.1 \\
\hline & $33 / 0$ & 31 & 81 & 11.5 \\
\hline 36 & $2 / 2$ & 29 & 63 & 12.0 \\
\hline \multirow[t]{3}{*}{37} & $12 / 0$ & 36 & 107 & 12.8 \\
\hline & $10 / 0$ & 40 & 134 & 14.7 \\
\hline & $8 / 0$ & 35 & 162 & 16.1 \\
\hline 38 & $0 / 17$ & 22 & 68 & 12.0 \\
\hline \multirow[t]{2}{*}{39} & $9 / 0$ & 23 & 58 & 7.0 \\
\hline & $8 / 0$ & 22 & 60 & 9.5 \\
\hline \multirow[t]{3}{*}{40} & $13 / 0$ & 28 & 58 & 10.8 \\
\hline & $16 / 0$ & 28 & 58 & 10.4 \\
\hline & $19 / 0$ & 28 & 64 & 10.8 \\
\hline 41 & $14 / 0$ & 40 & 91 & 10.8 \\
\hline 42 & $0 / 14$ & 22 & 73 & 14.6 \\
\hline 24 & $1 / 3$ & 26 & 78 & 13.6 \\
\hline \multirow[t]{3}{*}{43} & $9 / 0$ & 40 & 64 & 10.3 \\
\hline & $15 / 0$ & 38 & 68 & 9.2 \\
\hline & $8 / 0$ & 38 & 68 & 8.2 \\
\hline \multirow[t]{2}{*}{44} & $0 / 24$ & 23 & 72 & 14.1 \\
\hline & $10 / 0$ & 25 & 55 & 9.9 \\
\hline \multirow[t]{2}{*}{45} & $8 / 0$ & 23 & 57 & 11.1 \\
\hline & $8 / 0$ & 25 & 84 & 12.0 \\
\hline \multirow[t]{2}{*}{46} & $27 / 0$ & 32 & 62 & 9.3 \\
\hline & $20 / 0$ & 38 & 67 & 8.2 \\
\hline \multicolumn{5}{|c|}{ Third world } \\
\hline \multirow[t]{2}{*}{47} & $0 / 8$ & 34 & 61 & 20.3 \\
\hline & $0 / 8$ & 36 & 62 & 17.0 \\
\hline 48 & $0 / 8$ & 25 & 61 & 16.2 \\
\hline 49 & $7 / 0$ & 26 & 50 & 9.5 \\
\hline 50 & $14 / 0$ & 21 & 54 & 7.2 \\
\hline 51 & $0 / 6$ & 27 & 55 & 11.4 \\
\hline 52 & $10 / 0$ & 32 & 49 & 10.1 \\
\hline 53 & $15 / 0$ & 36 & 54 & 8.7 \\
\hline \multirow[t]{2}{*}{54} & $40 / 0$ & 43 & 65 & 9.5 \\
\hline & $0 / 33$ & 43 & 73 & 12.1 \\
\hline
\end{tabular}

Abbreviation: DEE, daily energy expenditure.

demands preceded any available direct measurements. It is impossible to test this directly. However, an indirect assessment can be made by comparing the energy demands of 
individuals in Western society with the energy demands of individuals living in non-Westernized rural societies in the third world (Table 2). Several studies of such populations have been made using the DLW method and we compiled data form the literature on their levels of expenditure and compared them to the data from Maastricht and North America using standard general linear modelling with gender as a factor and age and body mass as covariates.

It might be argued that whatever community is chosen in the modern world their levels of activity may be lower than levels historically in pre-Westernized societies. If modifications to our environment that reduced our energy demands precede the 1980s, and are not well reflected by the third world populations then we should be able to pick this up by reductions in our demands relative to that expected for equivalent-sized wild mammals as suggested previously. ${ }^{32}$ The fourth source of information we analysed therefore was for all the published data on wild terrestrial mammals using the DLW method. Although the DLW method was invented during the 1950s work on wild mammals did not start until the 1970s. We surveyed the literature between 1970 and 2005 for measurements of energy demands using the DLW method on free-living wild mammals. We searched the same databases as used for the human literature search including only studies on wild free-living terrestrial mammals. We included only peer-reviewed publications and excluded data on domesticated mammals and those involved in unusual activity (for example dogs in sled dog races). We did not exclude data pertaining to mammals in reproduction because often these were not separated in the original papers from data on non-reproductive animals. None of the data refer to mammals in hibernation states. Many studies of wild mammals report data collected in different seasons, under different environmental conditions. Moreover, for some species there are multiple studies by different authors pertaining to populations at different field sites. Because ambient temperature varies both seasonally and with different study locations, and because ambient temperature is a key variable driving energy demands, ${ }^{55}$ we collated the data for different seasons and study sites separately. In total we obtained 207 measurements of 90 different terrestrial mammal species and we obtained estimated ambient temperature measurements at the study sites for 167 of them. Many studies of wild mammal DEE include estimates of BEE in the thermoneutral zone for the same mammals studied using DLW. We supplemented these direct estimates using data on BEE for eight species from the review of White and Seymour ${ }^{56}$ yielding a total of 163 BEE estimates from which we could calculate the PAL.

Two factors are likely to make our prediction of the energy demands of modern humans from the relationships derived in wild mammals slightly overestimates. First, we did not exclude measurements of wild mammals engaged in reproductive activities that are likely to elevate energy requirements. We did this because data reported for reproductive and non-reproductive animals were often not separated in the original papers. Second, as we have previously highlighted, ${ }^{57}$ the routine methods for calculating energy demands by DLW have been differently applied by workers studying wild mammals compared with humans. The reasons for this difference are historical and reflect the fact that validation studies for small mammals, suggest a singlepool model is most appropriate, whereas in humans a twopool model seems to work best. ${ }^{24}$ A comprehensive review ${ }^{25}$ of validation studies of different-sized mammals concluded that the two-pool model is probably most appropriate for mammals weighing more than $4 \mathrm{~kg}$. Yet workers on mammals weighing more than $4 \mathrm{~kg}$ have routinely used the single-pool model calculation. The single-pool model gives a higher estimate of DEE than the two-pool model (by between 4 and 10\%) but re-calculating the data for mammals over $4 \mathrm{~kg}$ is not possible because the required data to make these recalculations are generally not provided in the original publications. These two factors mean that there will be a tendency for the predicted energy demands for mammals $>4 \mathrm{~kg}$ to be slightly overestimated.

\section{Results}

Using the Maastricht database ( $n=366$ subjects; Table 1$)$ we evaluated the trends in time of physical activity energy expenditure calculated in three different ways. There was a highly significant positive relationship between DEE and BEE with an $r^{2}$ of $53 \%$. We calculated the residuals to the fitted regression on this relationship and then explored the trends of these residuals with date of study. There was a slight but significant $(\mathrm{F}=3.89, P=0.049)$ trend for the residual of DEE on BEE to increase between 1988 and 2006 (Figure 1a) suggesting activity energy expenditure has slightly increased over the past two decades. Second, we calculated PAL, and explored trends of PAL over time (Figure 1b). There was no significant increase in PAL between 1988 and $2006(\mathrm{~F}=2.91$, $P=0.089)$. Finally, we included DEE in a generalized linear model with body mass, age, gender and the date of publication and their interactions as predictors. None of the two-way and higher interaction terms were significant. The major effect on DEE was body mass, explaining $32 \%$ of the variance. There were additional significant effects of age (lower DEE as get older) and gender (women lower independent of body mass and age). Together these factors and body mass explained $54 \%$ of the variation in DEE. However, there was no significant effect of the date of measurement $(\mathrm{F}=0.40, P=0.529$; Figure $1 \mathrm{c})$. Over the same time period that these measurements were made, rates of obesity in the Netherlands doubled from 5 to $10 \% .{ }^{58}$

Rates of obesity in North America increased over the same period, from 8 to $22 \%{ }^{1}$ The second set of DEE data for 393 subjects from North America were measured using DLW over approximately the same interval. The dominant factors influencing energy expenditure were body mass and gender. 

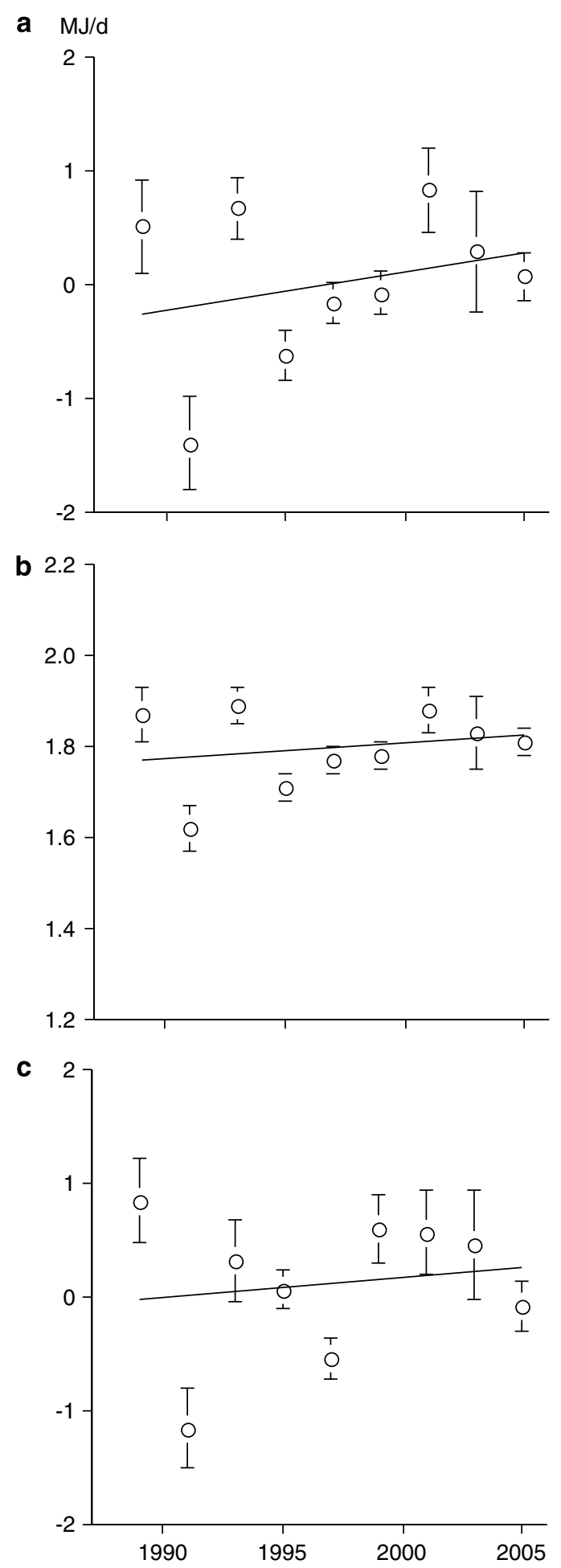

Figure 1 Trends in physical activity energy expenditure (MJ per day, mean \pm s.e.) over time (year of publication) for a population in Northern Europe (Maastricht). (a) The residual of the regression of daily energy expenditure (DEE) on basal energy expenditure (BEE); (b) physical activity level (PAL) which is the ratio of DEE to BEE; (c) the residual of the regression of DEE on body mass, sex and age.

In these data there was a significant positive effect $(\mathrm{F}=4.89$, $P=0.028$ ) of the date of measurement on levels of DEE adjusted for body mass, gender and age, again suggesting activity expenditure has increased over the past two decades.

The third set of DEE data, consisting of compiled DLW data from the third world countries, was compared with those from Maastricht and North America. In this combined data set there were significant effects of body mass $(\mathrm{F}=35.43, \quad P<0.001)$ and gender $(\mathrm{F}=116.07, \quad P<0.001)$. Although there were some groups of subjects that had high rates of expenditure in the third world, for example a small group of male subjects studied in the Gambia, overall across all studies the impact of whether the measurements were from Maastricht, North America or the third world was not significant $(\mathrm{F}=1.10, P=0.297)$. Thus, the DEEs of individuals from the most rural third world communities lie on the expected line determined by gender, age and body mass for individuals in Western societies.

To compare modern humans with wild mammals, literature data on DEE of wild mammals determined with the DLW method were compiled. The major factors influencing DEE were body mass (Figure 2a), and ambient temperature. The best-fit regression equation was Ln DEE (kJ per day$2.353+0.649$ Ln (body mass,g) $-0.0256 \mathrm{Temp}\left({ }^{\circ} \mathrm{C}\right)$ that explained $92.0 \%$ of the variation in DEE $(n=167)$. Knowing the body mass and ambient temperature at which a wild animal lives, allows a prediction of its expected daily energy demands. We used this equation to predict the energy demands expected for modern humans (averaging a body mass of $78.6 \mathrm{~kg}$ - the mean mass of the subjects measured at Maastricht) and living at typical room temperatures of $20^{\circ} \mathrm{C}$, which yielded $9.16 \mathrm{MJ}$ per day $(95 \% \mathrm{CI}=7.9-2.9 \mathrm{MJ}$ per day). The actual expenditure across all the Maastricht data was 12.6 MJ per day. A review of 574 measurements made using the DLW method on subjects worldwide published in 1996 gave an average value (for adults excluding athletes) of 11.2 MJ per day ${ }^{30}$ and our own summary for data in the United States gives a weighted average of $10.9 \mathrm{MJ}$ per day (lower body weight $(70.5 \mathrm{~kg}$ ) because of $85 \%$ women in the sample). None of these values is lower than the prediction based upon average body mass and room temperatures. Moreover, all the suggested potential biases indicate that the prediction from wild mammals would likely if anything be an overestimate.

\section{Discussion}

Using a variety of different techniques to analyse the data on DEE and BEE, we evaluated how levels of activity energy expenditure have changed over time since the first uses of the DLW method in the 1980s. Independent of the method used, there was no indication that energy expenditure on physical activity or total expenditure has declined over the past two decades in Northern Europe (Maastricht). Indeed

International journal of Obesity 

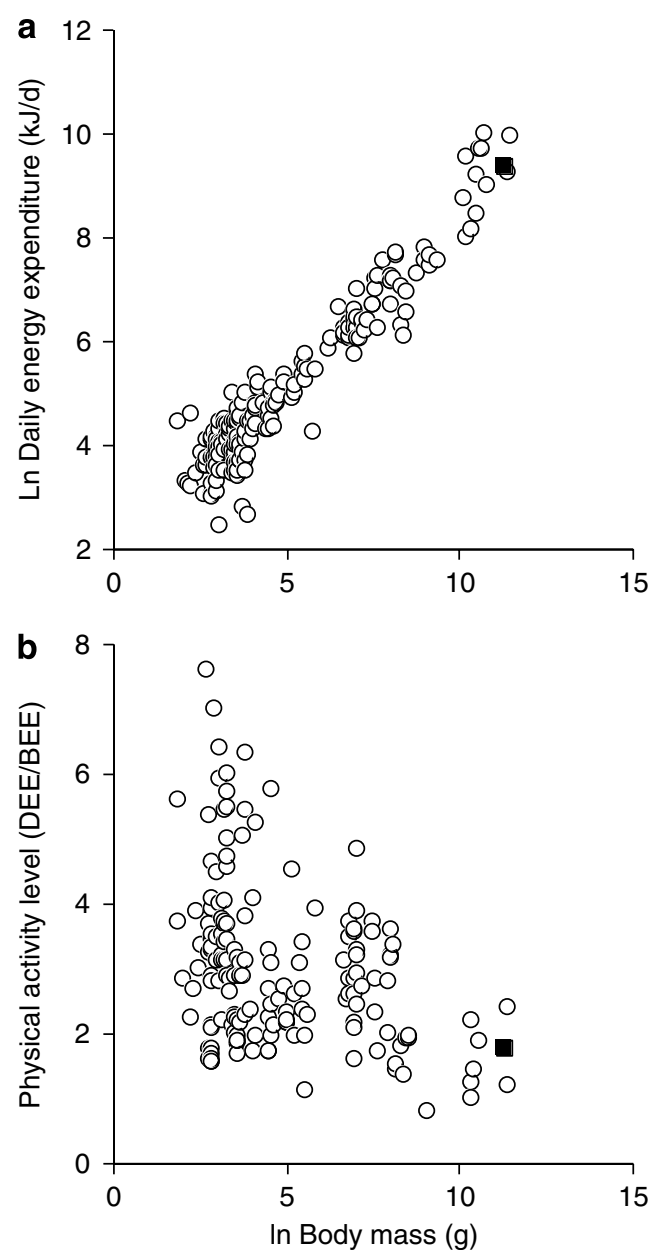

Figure 2 (a) Effect of body mass on daily energy expenditure (DEE) in wild terrestrial mammals; (b) effect of body mass on the ratio of DEE to basal energy expenditure (BEE) for terrestrial mammals. In both plots the value for humans is indicated as a closed square.

the trends when significant were actually in the opposite direction - suggesting levels of activity energy expenditure may have actually increased over this time interval. Similar data trends were apparent in data compiled from across North America using the only analysis method that was possible to apply to this data set. Over the same period that we have data for DEE, obesity has increased from 8 to $11 \%$ in the Netherlands and from 14 to $22 \%$ in North America. The trend for an increase in activity energy expenditure in time possibly resulted from an increase in body weight, with a consequent increase in the cost of moving around. ${ }^{26}$

Given that the data from Maastricht were collected from a relatively small population around a single city, by a single research group, and included subjects that were measured either as controls, pre-intervention or non-intervention groups the sample is probably a representative sample of the population. This is important because the absence of a trend in energy expenditure with time in this analysis is founded on the assumption that the sample included in the analysis is unbiased. The same cannot be said for the sample from North America that included mostly women (85\%) and was drawn from an ethnically diverse background across an enormous geographic range. The positive trend of expenditure with time in this sample may thus be a sampling artefact. Nevertheless, it is reassuring that the data from North America did not contradict the much better controlled sample from Europe. Unfortunately, these data are the best data we have. Accepting the potential caveats in the American data we suggest it is unlikely that decreased activity energy expenditure is responsible for these phases of the obesity epidemic in the respective continents. Surprisingly, DEE of modern humans in Westernized societies was also completely in line with estimates for people measured in the third world countries, and the predicted DEE from an equation derived from measurements of wild terrestrial mammals. These latter data suggest that even earlier phases of the epidemic were probably also not triggered by lowered levels of activity energy expenditure due to reduced PALs.

These data would seem to be at odds with anecdotal suggestions that levels of physical activity have declined over time ${ }^{15}$ and direct observations that the obese are less physically active than their lean counterparts. This phenomenon has caused an obvious misunderstanding. Ekelund et al. ${ }^{28}$ compared the energy expended on activity as well as direct observations of body movement in obese (BMI > 30) and matched non-obese adolescents. Although the obese subjects performed less physical activity than the non-obese, there was no difference in their expenditure of energy on activity. Obese subjects move less, but this does not necessarily mean they have a lower energy expenditure on activity, because energy expenditure while they are active is higher. Very few longitudinal data exist but our analysis and conclusions are consistent with observations that weight gain by individual Pima Indians over a 4-year interval was not correlated to their initial levels of physical activity energy expenditure, but rather positively linked to their total energy intake. ${ }^{59}$

Our analysis of human energy demands relative to those of wild mammals is discrepant with a previous comparison that concluded humans have lower energy demands than expected. ${ }^{32}$ The reason for this discrepancy is because the previous study compared PAL values between humans and other species, but did not account for the effects of body mass on PAL. PAL values are calculated using the resting energy at thermoneutral conditions (BEE) under the assumption that the remaining energy demand predominantly fuels activity. This is only correct, however, when the DEE is also measured at thermoneutrality, as it is in humans. For many wild mammals measures of DEE are made at ambient temperatures below the relevant thermoneutral zone, hence PAL for these mammals reflects the combination of activity metabolism and the energy spent on thermoregulation. In fact PAL calculated as (DEE/BEE) is negatively related to body 
mass (Figure $2 \mathrm{~b}$ ) reflecting the increasing thermoregulatory load as body size declines. Hence, PAL for contemporary humans is at the lower end of the distribution of PAL values when the effects of body mass are ignored, in line with the previous findings, ${ }^{30}$ but they are at exactly the expected level, once the effect of body mass on PAL is taken into account (Figure $2 b$ ).

In conclusion, energy expenditure in Europe and North America has not declined between the 1980s and 2005, a period during which obesity rates have increased. Neither is energy expenditure in Western society lower than in the third world, nor than expected from measures of wild terrestrial mammals. Of course, obesity can only result from an imbalance between intake and expenditure. On the basis of these analyses, the data indicate that reduced energy expenditure due to lowered physical activity expenditure is unlikely to have fuelled the obesity epidemic.

\section{References}

1 Spiegel AM, Alving BM. Executive summary of the strategic plan for National Institutes of Health Obesity Research. Am J Clin Nutr 2005; 82: 211S-2114S.

2 NIH ORTF. Strategic Plan for NIH Obesity Research. US Department of Health and Human Services: Bethesda, MD, 2004.

3 Seidell JC. Obesity and weight control: the evidence. Proc Nutr Soc 2000; 59: 419-420.

4 Wadden TA, Brownell KD, Foster GD. Obesity: responding to the global epidemic. J Consult Clin Psychol 2002; 70: 510-525.

5 Kopelman PG. Obesity as a medical problem. Nature 2000; 404: 635-643.

6 Eisenmann JC, Katzmarzyk PT, Perusse L, Tremblay A, Despres JP, Bouchard C. Aerobic fitness, body mass index, and CVD risk factors among adolescents: the Quebec family study. Int $J$ Obes 2005; 29: 1077-1083

7 Batty GD, Shipley MJ, Jarrett RJ, Breeze E, Marmot MG, Smith GD. Obesity and overweight in relation to organ-specific cancer mortality in London (UK): findings from the original Whitehall study. Int J Obes 2005; 29: 1267-1274.

8 Wolf AM, Colditz GA. Current estimates of the economic cost of obesity in the United States. Obes Res 1998; 6: 97-106.

9 Kortt MA, Langley PC, Cox ER. A review of cost-of-illness studies on obesity. Clin Ther 1998; 20: 772-779.

10 WHO. Obesity: Preventing and Managing a Global Epidemic. WHO: Geneva, 1998.

11 Speakman JR. Obesity: the integrated roles of environment and genetics. J Nutr 2004; 134: 2090S-2105S.

12 Kral TV, Roe LS, Rolls BJ. Combined effects of energy density and portion size on energy intake in women. Am J Clin Nutr 2004; 79: 962-968.

13 Kral TV, Rolls BJ. Energy density and portion size: their independent and combined effects on energy intake. Physiol Behav 2004; 82: 131-138.

14 Ferro-Luzzi A, Martino L. Obesity and physical activity. Ciba Found Symp 1996; 201: 207-227.

15 Prentice AM, Jebb SA. Obesity in Britain: gluttony or sloth? BMJ 1995; 311: 437-439.

16 Binkley JK, Eales J, Jekanowski M. The relation between dietary change and rising US obesity. Int J Obes 2000; 24: 1032-1039.

17 Cavadani C, Siega-Riz AM, Popkin BM. US adolescent food intake trends from 1965 to 1996 . West J Med 2000; 173: 378-383.

18 Willett WC, Leibel RL. Dietary fat is not a major determinant of body fat. Am J Med 2002; 113 (Suppl 9B): 47S-59S.
19 Brownson RC, Boehmer TK, Luke DA. Declining rates of physical activity in the United States: what are the contributors? Annu Rev Public Health 2005; 26: 421-443.

20 Goran MI, Hunter G, Nagy TR, Johnson R. Physical activity related energy expenditure and fat mass in young children. Int J Obes 1997; 21: 171-178.

21 Brooks GA, Butte NF, Rand WM, Flatt JP, Caballero B. Chronicle of the Institute of Medicine physical activity recommendation: how a physical activity recommendation came to be among dietary recommendations. Am J Clin Nutr 2004; 79: 921S-930S.

22 Balanza R, Garcaa-Lorda P, Paorez-Rodrigo C, Aranceta J, Bonet $\mathrm{MB}$, Salas-Salvada J. Trends in food availability determined by the Food and Agriculture Organization's food balance sheets in Mediterranean Europe in comparison with other European areas. Public Health Nutr 2007; 10: 168-176.

23 Silventoinen K, Sans S, Tolonen H, Monterde D, Kuulasmaa K, Kesteloot $\mathrm{H}$, et al., WHO MONICA Project. Trends in obesity and energy supply in the WHO MONICA Project. Int J Obes 2004; 28: 710-718

24 Schoeller DA, Van Santen E. Measurement of energy expenditure in humans by doubly labelled water method. J Appl Physiol 1982; 53: 955-959.

25 Speakman JR. Doubly-labelled Water: Theory and Practice. Chapman and Hall: London, 1997.

26 Schoeller DA. How accurate is self-reported dietary energy intake? Nutr Rev 1990; 48: 373-379.

27 Westerterp KR, Goris AHC. Validity of the assessment of dietary intake: problems of misreporting. Curr Opin Clin Nutr Metab Care 2002; 5: 489-493.

28 Ekelund U, Aman J, Yngve A, Renman C, Westerterp K, Sjostrom M. Physical activity but not energy expenditure is reduced in obese adolescents: a case-control study. Am J Clin Nutr 2002; 76: 935-941.

29 WHO. Human Energy Requirements. FAO/WHO/UNU: Rome, 2004.

30 Black AE, Coward WA, Cole TJ, Prentice AM. Human energy expenditure in affluent societies: an analysis of 574 doublylabelled water measurements. Eur J Clin Nutr 1996; 50: 72-92.

31 Westerterp KR. Alterations in energy balance with exercise. Am J Clin Nutr 1998; 68: 970S-974S.

32 Hayes M, Chustek M, Heshka S, Wang Z, Pietrobelli A, Heymsfield SB. Low physical activity levels of modern Homo sapiens among free-ranging mammals. Int J Obes 2005; 29: $151-156$

33 Westerterp KR, Wouters L, van Marken Lichtenbelt WD. The Maastricht protocol for the measurement of body composition and energy expenditure with labeled water. Obes Res 1995; 3 (Suppl 1): 49-57.

34 Westerterp KR. Body composition, water turnover and energy turnover assessment with labelled water. Proc Nutr Soc 1999; 58: 945-951.

35 Butte NF, Treuth MS, Mehta NR, Wong WW, Hopkinson JM, O'Brien Smith E. Energy requirements of women of reproductive age. Am J Clin Nutr 2003; 77: 630-638.

36 Calazel CM, Young VR, Evans WJ, Roberts SB. Effect of fasting and feeding on measurement of carbon dioxide production using doubly labelled water. Am J Physiol 1993; 74: 1824-1829.

37 Das SK, Saltzman E, McCrory MA, Hsu LKG, Shikora SA, Dolnikowski $\mathrm{G}$ et al. Energy expenditure is very high in extremely obese women. J Nutr 2004; 134: 1412-1416.

38 Goran MI, Beer WH, Wolfe RR, Poehlman ET, Young VR. Variation on total energy expenditure in young healthy freeliving men. Metab 1993; 42: 487-496.

39 Melby CL, Ho RC, Jeckel K, Beal L, Goran M, Donahoo WT. Comparison of risk factors for obesity in young, nonobese African-American and Caucasian women. Int J Obes 2000; 24: 1514-1522.

40 Poehlman ET, Denino WF, Beckett T, Kinaman KA, Dionne IJ, Dvorak R et al. Effect of endurance and resistance training on 
total daily energy expenditure in young women: a controlled randomized trial. J Clin Endocrinol Metab 2002; 87: 1004-1009.

41 Racette SB, Schoeller DA, Kushner RF. Comparison of heart rate and physical activity recall with doubly labelled water in obese women. Med Sci Sports Exerc 1995; 27: 126-133.

42 Roberts SB, Heyman MB, Evans WJ, Fuss P, Tsay R, Young VR. Dietary energy requirements of young adult men, determined by using the doubly labelled water method. Am J Clin Nutr 1991; 54: 499-505.

43 Schoeller DA, Shay K, Kushner R. How much physical activity is needed to minimize weight gain in previously obese women? Am J Clin Nutr 1997; 66: 551-556.

44 Vinken AG, Bathalon GP, Sawaya AL, Dallal GE, Tucker KL, Roberts SB. Equations for predicting the energy requirements of healthy adults aged 18-81 y. Am J Clin Nutr 1999; 69: 920-926.

45 Weber JL, Reid PM, Greaves KA, DeLany JP, Stanford VA, Going SB et al. Validity of self-reported energy intake in lean and obese young women, using two nutrient databases, compared with total energy expenditure assessed by doubly labelled water. Eur J Clin Nutr 2001; 55: 940-950.

46 Weinsier RL, Hunter GR, Desmond RA, Byrne NM, Zuckerman PA, Darnell BE. Free-living activity energy expenditure in women successful and unsuccessful at maintaining a normal body weight. Am J Clin Nutr 2002; 75: 499-504.

47 Diaz E, Goldberg GR, Taylor M, Savage JM, Sellen D, Coward WA et al. Effects of dietary supplementation on work performance in Gambian laborers. Am J Clin Nutr 1991; 53: 803-811.

48 Heini AF, Minghelli G, Diaz E, Prentice AM, Schutz Y. Free-living energy expenditure assessed by two different methods in rural Gambian men. Eur J Clin Nutr 1996; 50: 284-289.

49 Heini A, Schutz Y, Diaz E, Prentice AM, Whitehead RGG Jéquier $\mathrm{E}$. Free-living energy expenditure measured by two independent techniques in pregnant and nonpregnant Gambian women. Am I Physiol 261; 24: E9-E17.
50 Huss-Ashmore R, Goodman JL, Sibiya TE, Stein TP. Energy expenditure of young Swazi women as measured by the doubly-labelled water method. Eur J Clin Nutr 1989; 43: 737-748.

51 Riumallo JA, Schoeller D, Barrera G, Gattas V, Uauy R. Energy expenditure in underweight free-living adults: impact of energy supplementation as determined by doubly labeled water and indirect calorimetry. Am J Clin Nutr 1989; 49: 239-246.

52 Singh J, Prentice AM, Diaz E, Coward WA, Ashford J, Sawyer M et al. Energy expenditure of Gambian women during peak agricultural activity measured by the doubly-labelled water method. Br J Nutr 1989; 62: 315-329.

53 Stein TP, Johnston FE, Greiner L. Energy expenditure and socioeconomic status in Guatemala as measured by the doubly labelled water method. Am J Clin Nutr 1988; 47: 196-200.

54 Yao M, McCrory MA, Ma G, Li Y, Dolnikowski GG, Roberts SB. Energy requirements of urban Chinese adults with manual or desentary occupations, determined using the doubly labeled water method. Eur J Clin Nutr 2002; 56: 575-584.

55 Speakman JR. The cost of living: field metabolic rates of small mammals. Adv Ecol Res 2000; 30: 177-297.

56 White CR, Seymour RS. Mammalian basal metabolic rate is proportional to body mass ${ }^{2 / 3}$. Proc Natl Acad Sci USA 2003; 100: 4046-4049.

57 Speakman JR. How should we calculate $\mathrm{CO}_{2}$ production in doubly-labelled water studies of mammals? Funct Ecol 1993; 7: 746-750.

58 Visscher TL, Kromhout D, Seidell JC. Long-term and recent time trends in the prevalence of obesity among Dutch men and women. Int J Obes 2002; 26: 1218-1224.

59 Tataranni PA, Harper IT, Snitker S, Del Parigi A, Vozarova B, Bunt J et al. Body weight gain in free-living Pima Indians: effect of energy intake vs expenditure. Int J Obes 2003; 27: 1578-1593. 